Artvin Çoruh Üniversitesi

Orman Fakültesi Dergisi

ISSN:2146-1880, e-ISSN: 2146-698X

Yıl: 2020, Cilt: 21, Sayı:1, Sayfa: 68-74

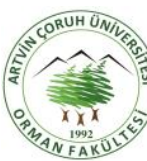
Journal of Forestry Faculty ISSN:2146-1880, e-ISSN: 2146-698X

Year: 2020, Vol: 21, Issue: 1, Pages: 68-74

ofd.artvin.edu.tr

(c) (i)

\title{
Kuzey Kıbrıs Lefke bölgesi yerel hurma (Phoenix dactylifera L.) genotiplerinin belirlenmesi ve pomolojik özellikleri
}

\section{Determination of local Date Palm (Phoenix dactylifera L.) genotypes and pomological characteristics in Lefke region of Northern Cyprus}

Nihat YILMAZ ${ }^{1}$

${ }^{1}$ Kayseri Üniversitesi, Safiye Çıkrıkçıoğlu Meslek Yüksekokulu, Kayseri, TÜRKiYE

\section{Eser Bilgisi / Article Info}

Araştırma makalesi / Research article

DOI: 10.17474 /artvinofd.634888

Sorumlu yazar / Corresponding author Nihat YILMAZ

e-mail: nihatyilmaz@kayseri.edu.tr

Geliş tarihi / Received

19.10.2019

Düzeltme tarihi / Received in revised form

04.01.2020

Kabul Tarihi / Accepted

12.01.2020

Elektronik erişim / Online available

12.03.2020

\section{Anahtar kelimeler:}

Hurma (Phoenix dactylifera L.)

Yerel genotipler

Kuzey Kıbrıs

\section{Keywords:}

Date Palm (Phoenix dactylifera L.)

Local genotype

Northern Cyprus

\begin{abstract}
Özet
Araştırma, Kuzey Kıbrıs'ta yeşilin ve mavinin kesişme noktasında yer alan Lefke bölgesi ve çevresinde (Yedidalga, Çamlıköy, Cengizköy, Yeşilyurt, Doğancı, Gemikonağı Gaziveren) doğal olarak yetişen hurma genotiplerinin bir envanterinin çıkarılması ve ümit verici genotiplerin belirlenmesi amacıyla yürütülmüştür. Kuzey Kıbrıs'ta uzun yıllar boyunca yetiştiriciliği yapılan hurma ağaçlarının bölge ekonomisine olan katkısının artırılması ve ekonomiye kazandırılması amacıyla araştırma materyallerini oluşturan hurma ağaçlarının taraması yapılmış ve dioik bitki olması nedeniyle meyve veren dişilerle ve erkek ağaçlarının sayısı belirlenmiştir. Yetiştiriciliği yapılan bu yerel kaynakların meyve veren ağaçlarda yapılan pomolojik analizler neticesinde ümit verici genotipler belirlenmiş ve bu belirlenen genotiplerin meyvelerine ait meyve ağırlığı $(\mathrm{g})$, meyve boyu $(\mathrm{mm})$, meyve eni $(\mathrm{mm})$ ve tohum ağırlığı $(\mathrm{g})$ gibi bazı pomolojik özellikleri belirlenmiştir. Çalışmalar neticesinde bölgesel anlamda toplam hurma varlığı 1512 olarak tespit edilmiştir. Bu belirlenen sayı içerisinde dişi hurma sayısı 1176 adet ve geriye kalan 336 adedi ise erkek hurmalardan oluşmaktadır. Pomolojik analizlerde genotipler arasında ortalama meyve ağırlıkları $8.91 \mathrm{~g}$ ile $15.29 \mathrm{~g}$ arasında değişmiştir. Bu bilgiler ışığında kayıt altına alınan bu genotiplerinin adada yapılan ilk olma niteliği ile ileride yapılacak bilimsel çalışmalara ışık tutacağı düşünülmektedir.
\end{abstract}

\begin{abstract}
The study was carried out in order to obtain an inventory of local date palm genotypes that grow naturally in Lefke region and environs (Yedidalga, Çamlıköy, Cengizköy, Yeşilyurt, Doğancı, Gemikonağı and Gaziveren) located at the intersection point of green and blue in Northern Cyprus and determination of hopeful genotypes. The date palm trees using the research materials were screened and the number of male and female trees giving fruit was determined due to the fact that they were dioic. In this context, the hopeful genotypes were determined as a result of the pomological analysis of fruit trees and some pomological characteristics such as fruit weight $(\mathrm{g})$, fruit length $(\mathrm{mm})$, fruit width $(\mathrm{mm})$ and seed weight $(\mathrm{g})$ were determined at fruit ripening stages called tamar stage from these genotypes. As a result of the study, the total date palm tree asset in the regional sense was determined as 1512. In this determined number, the number of the female date palm was found 1176 in total date palm and the remaining 336 was male tree. The average fruit weight in pomological analyzes ranged from $8.91 \mathrm{~g}$ to $15.29 \mathrm{~g}$. It is thought that these genotypes recorded in light of this information will be the first on the island to shed light on future scientific studies.
\end{abstract}

\section{Giriş}

Yaprağını dökmeyen meyveler grubu içerisinde yer alan ve 30 m'ye kadar boylanabilen hurma (Phoenix dactylifera L.), Kuzey Afrika ve Ortadoğu' da 5000 yıllık bir geçmişe sahip olan bir meyvedir (Karut ve Kazak 2005, Süleymani 2012, Faqir ve ark. 2017). Geniş bir yetişme alanına sahip olan hurma, Ortadoğu'dan özellikle Mezopotamya Bölgesi'nden (Irak'ın güneyi) Hindistan'a kadar geniş bir bölgeye yayılmıştır. Sıcağı, güneşi sever, soğuktan ise hoşlanmayan, tam bir besin deposu olan hurma, içerdiği çeşitli vitaminler, yağ, su, şeker ve mineral maddeler ile insan beslenmesinin vazgeçilmez meyvelerinden biridir (Al-Shahib ve Marshall 2003, Arias ve ark. 2016, Faqir ve ark. 2017, Khan 2015, Aladadi ve ark. 2018, Anonim 2018, Aslan ve Şanlıer 2018).

Taksononik olarak dünyada 5000'den fazla tanımlanmış ve Dioik bir yapıda bulunan hurma ağacı hem erkek ağacı hem de dişi ağacı bulunur ve ayrı bitkiler olarak yaşamlarını sürdürürler (Faqir ve ark. 2017, Aladadi 2018). Çoğaltılması her ne kadar tohumla olsa da modern 
yetiştiricilikte çelikle üretilmesi önerilmektedir. Çelikle çoğaltılan fidanlar tohumla üretilen fidanlara göre 2-3 yıl daha erken meyveye yatmaktadır. Ayrıca, meyve kalitesi ve verim de çelikle çoğaltılanlarda daha yüksektir. Rüzgâr ile tozlanmasına rağmen birçok üretici elle tozlanmaya katkıda bulunmaktadır. Erkek bitkilerin polen salkımlarını dişi bitkinin ağacına asmak suretiyle bu işlemi gerçekleştirmektedirler. Yılda bir kez meyve vermekte olan hurma, tozlaşmadan itibaren tam olgunluğa kadar 5 farklı aşamadan geçmekte ve bu süre yaklaşık olarak 7-8 ay sürmektedir. Hurma meyveleri salkım şeklinde ve ortalama salkım ağırı̆̆ı $10 \mathrm{~kg}$ civarındadır (Süleymani 2012, Aslan ve Şanlıer 2018, Anonim 2018)
Hurma gelişme dönemine göre 5 ayrı aşamadan oluşmakta (Şekil 1) ve uluslararası kabul gören bu aşamaların adı Arapçadan gelmektedir (Anonim 2018, Anonim 2019a).

1. "Hababouk"

2. "Kimri"

3. "Khalal"

4. "Rutab"

5. "Tamr"

Aşamaların ilk üç evresinde hurmanın yenmesi pek tavsiye edilmez. Ancak hurma "Rutab" yani taze hurma ve son dönem olan "Tamar" yani kuru hurma durumuna ulaştı̆̆ında tüketilmesi tavsiye edilmektedir.

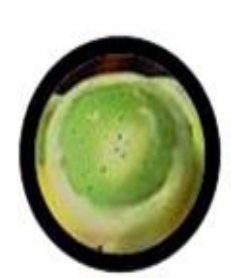

Hababouk

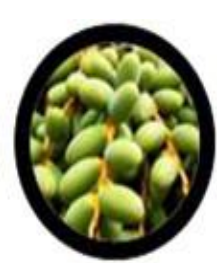

Kimri

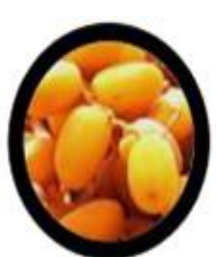

Khalal

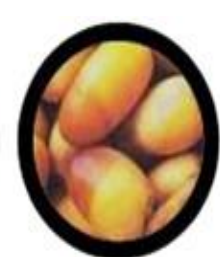

Rutab

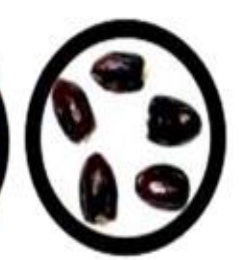

Tamar

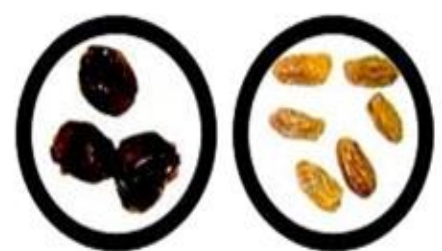

Tamar

Tamar

(Farad) (Khajur soft) (Khajur hard)

Şekil 1. Hurmanın olgunlaşma aşamaları

Bu aşamalar sırasıyla;

1. Hababouk aşaması: Döllenmeden sonraki ilk aşamadır. Meyveler yaklaşık bezelye tanesi büyüklüğündedir.

2. Kimri aşaması (Yeşil aşama): iki aşamalı olarak gerçekleşir. Birinci aşamada, ağılık artışı, boy uzaması, şeker birikimi artar, asitlik ve nem içeriği yükselir. İkinci aşamada ise; ağılık artışı, boy uzaması oranı azalır, şeker birikim oranı düşer ve nem içeriği birinci aşamadan daha yüksek seviyeye ulaşır.

3. Khalal aşaması: Hurma meyve renginin değişmeye başladığı aşamadır. Renk çeşitlere bağlı olarak sarıdan kırmızıya kadar değişen bir renk alır (3-5 hafta). Meyve ağırlığında belirgin artışlar sağlanır. Besin içeriği de zenginleşmeye başlar.

4. Rutab aşaması (Yumuşak olgunluk): Bu aşama 2-4 hafta arasında sonlanır. Meyve bu aşamada su kaybetmeye ve yumuşamaya başlar.
5. Tamar aşaması (Tam olgunluk): Olgunlaşmanın son aşamasıdır. Hurmalar susuz ve artık koyu renkte görünür.

Bazı önemli hurma çeşitleri; Şekil ve biçim bakımından farklı 600 civarında çeşidi bulunmaktadır. Bu çeşitleri üç grupta incelemek mümkündür.

I.Grup: Yumuşak meyveli (Bazı önemli çeşitleri; 'Khadrawy', 'Medjool'), (Şekil 2).

- Khadrawy: Yumuşaktır ve meyve rengi koyudur.

- Medjool veya (Mujhoolah): Meyveleri iri, tatlı ve etlidir.

II. Grup: Yarı kuru meyveli (Bazı önemli çeşitleri; Deglet Noor' Zahidi')

III. Grup: Kuru meyveli (Önemli çeşidi 'Thoory') 


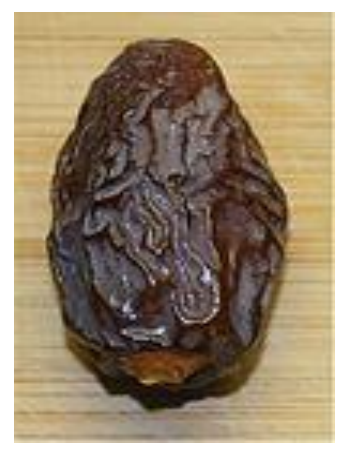

Medjool hurması

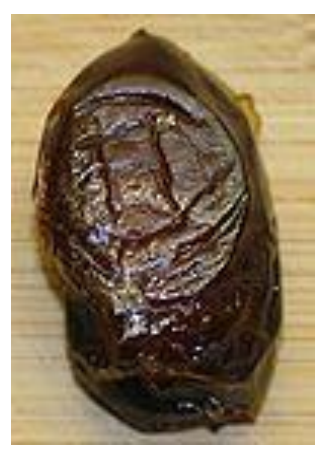

Khadrawy hurması

Şekil 2. Yumuşak meyveli olan bazı 1. Grup hurma meyvesi

\section{KKTC'YE GENEL BAKIŞ}

Akdeniz'in ortasında, Sardunya ve Sicilya adalarından sonra üçüncü büyük ada konumunda olan Kıbrıs adası, birçok göç ve ticaret yolunun beşiği konumunda bulunan ada florası ve bitki gen kaynakları bakımından oldukça zengindir (Yılmaz ve ark. 2012). Kuzey Kıbrıs Türk Cumhuriyeti (KKTC) $32-34^{\circ}$ doğu meridyenleri ile $34-35^{\circ}$ kuzey paralelleri arasında Akdeniz'in kuzey doğusunda yer almaktadır (Anonim 2017). Toplam olarak adanın yaklaşık yüzölçümü 9251 km2'dir. K.K.T.C'in yüz ölçümü ise 3298 km2' dir. Genel olarak tipik Akdeniz iklimi hüküm sürmektedir. Adanın coğrafik konumuna bakıldığında ise adanın Türk tarafında bulunan ve kuzey kıyılarına paralel olarak doğu batı yönünde bir uçtan bir uca uzanan Beşparmak dağları ve Rum kesiminde yer alan Trodos dağları yer alır. Bu iki dağ silsilesini birleştiren ise geniş, genellikle düzgün ve kurak olan Mesarya ovasıdır ki bu bölgenin batı kesiminde kalan ve hayat kaynağı suyun bulunduğu Batı Mesarya ovası yetiştiriciliğin yoğun olarak yapıldığı bölge konumundadır. Adanın doğusunda en uç kısmı oluşturan Karpaz yarımadasıdır. Ayrıca farklı iklim ve bitki örtüsü yapısına sahip olan ve sulu tarımın yoğun olarak yapıldığı çeşitli türlerden kurulmuş bahçelere sahip olan Lefke bölgesi bulunmaktadır.

\section{Lefke Bölgesi Hurma Yetiştiriciliği ve Önemi}

Kıbrıs'ta ilk hurmacılık, Lüzinyanlar ve Venedikliler döneminde başlamıştır. Lefke bölgesinde yer alan altın madenini çalıştıran bu ülkelerin madeni içeriden dışarıya taşımak için hurma yapraklarından yapılmış selelerden faydalandıkları bilinmektedir. Lefke'deki hurma ağaçlarının Mısırdan getirildiği de bilinmektedir.
Mısırıların, Lefke' de hangi tarihlerde bakır madenlerini işletmeye başladığı tam olarak bilinmiyor (Anonim 2019b).

Lefke bölgesinde yer alan mevcut hurmaların büyük bir bölümü verimlidir. Geriye kalan kısmı ise ekonomik bir değere sahip değildir. Lefke bölgesinde bulunan genç nüfusun başka dallara ve işlere yönelmesiyle hurma yetiştiriciliğine gereken önem gösterilmemiştir. Yöre halkının adına festivaller düzenlediği hurma tüketim şekilleri bakımından da kendine özgüdür. Öncelikle hasat edilen ve dallarında olgunlaşanlar "Ana Balçık" diye adlandırılır ve hemen tüketilir.

Dallar kesildikten sonra üç yöntemle olgunlaşma sağlanır;

1. Dallar kapalı bir yerde bekletilir ve hurmalar dallarda olgunlaştırılır.

2. Dallardan kopartılan hurmalar naylon torbalara alınıp buzdolabında dondurulur ve daha sonra oda sıcaklığında bir bez üstüne serilip bir veya iki gün bekletilerek olgunlaştırılır.

3. Dallardan meyve alınmadan üzerine sirke serpilip naylonla örterek olgunlaştırılır.

Dallardan kopartılan meyvelerden ayrıca hurma macunu yapılır. Bu ürün uzun süren zahmetli bir iş olmasına karşın, hurma macunu lezzetli bir ürün olarak tüketilir.

Bu çalışma ile uzun yıllardır ada şartlarına uyum sağlamış ve ekonomik anlamda verim sağlayan Lefke bölgesi ve civar köylerinde bulunan hurmalarının envanterinin çıkarılması sağlanmış ve elde edilen bilgiler ışı̆̆ında hem ülke ekonomisine hem de aile bütçesine katkı sağlayan 
tiplerin meyve pomolojik özellikleri belirlenmiş ve bu tiplerin bilimsel anlamda kayıt altına alınması gerçekleştirilmiştir. Bu çalışma bir ilk niteliğinde olup ileride yapılacak bilimsel çalışmalara ışık tutacağı düşünülmektedir.

\section{MATERYAL VE YÖNTEM}

Araştırma, Kuzey Kıbrıs'ta yer alan Lefke ilçe merkezlerinde ve ilçelere bağlı köylerinde (Gemikonağı, Yedidalga, Çamlıköy, Cengizköy, Yeşilyurt, Doğancı ve Gaziveren) tamamen doğal olarak yetişen hurmalar üzerinde yürütülmüştür. Meyveler ekim ayı sonundan kasım ayı ortalarına denk gelen zamanlarda ve Tamar aşamasında araziden toplanmıştır. Materyallerin kodlama işlemi aşağıdaki gibi yapılmıştır:

\section{Örnek Kayıt No: Hur-01}

- Genotip Adı: Alınan materyalin ait olduğu türün anlamlı ilk üç harfi; Burada Hurma "Hur" şeklinde kodlanmıştır.

- Kayıt Numarası: Genotipin toplandığı sıra numarası

\section{Yöntem}

\section{Anket çalışmaları}

Araştırmada bitki materyali olarak kullanılacak hurma genotiplerinin belirlenmesi amacıyla Lefke ilçe merkezde yer alan tarım ilçe müdürlüğü ile hurma hakkında iyi bilgiye sahip olan bölgedeki hurmalarla yıllarca ilgilenmiş Lefke bölgesi sakini olan ve bu işi tek başına yürüten "Hurmacı Savaş" olarak tanınan kişi ve bölge halkından hurmalar hakkında miktarları ve nerelerde daha yoğun oldukları hakkında bilgiler edinilmiştir. Edinilen bilgiler ışığında hurma yetişen ve/veya yetiştirilen bölgeler sınıflandırılmış ve bu sınıflandırmalar doğrultusunda ilk olarak Lefke bölgesinin en uç kısmını oluşturan Aplıç bölgesinde (Kıbrıs Rum kesimi ile K.K.T.C sınırının kesişen bölgesi) hurma sayımlarına başlanılmıştır. Bu bölgedeki hurma sahipleriyle birebir görüşmeler yapılmış ve hurma sayıları, erkek ve dişi olmak üzere bilgiler alınmıştır. Daha sonra bu hurmalar erkek ve dişi ağaçlar şeklinde sayımları yapılmış ve yerleri tespit edilerek etiketlenmiştir (Şekil 3). Aynı şekilde diğer bölgelerdeki çalışmalar da bu şekilde yürütülmüştür.

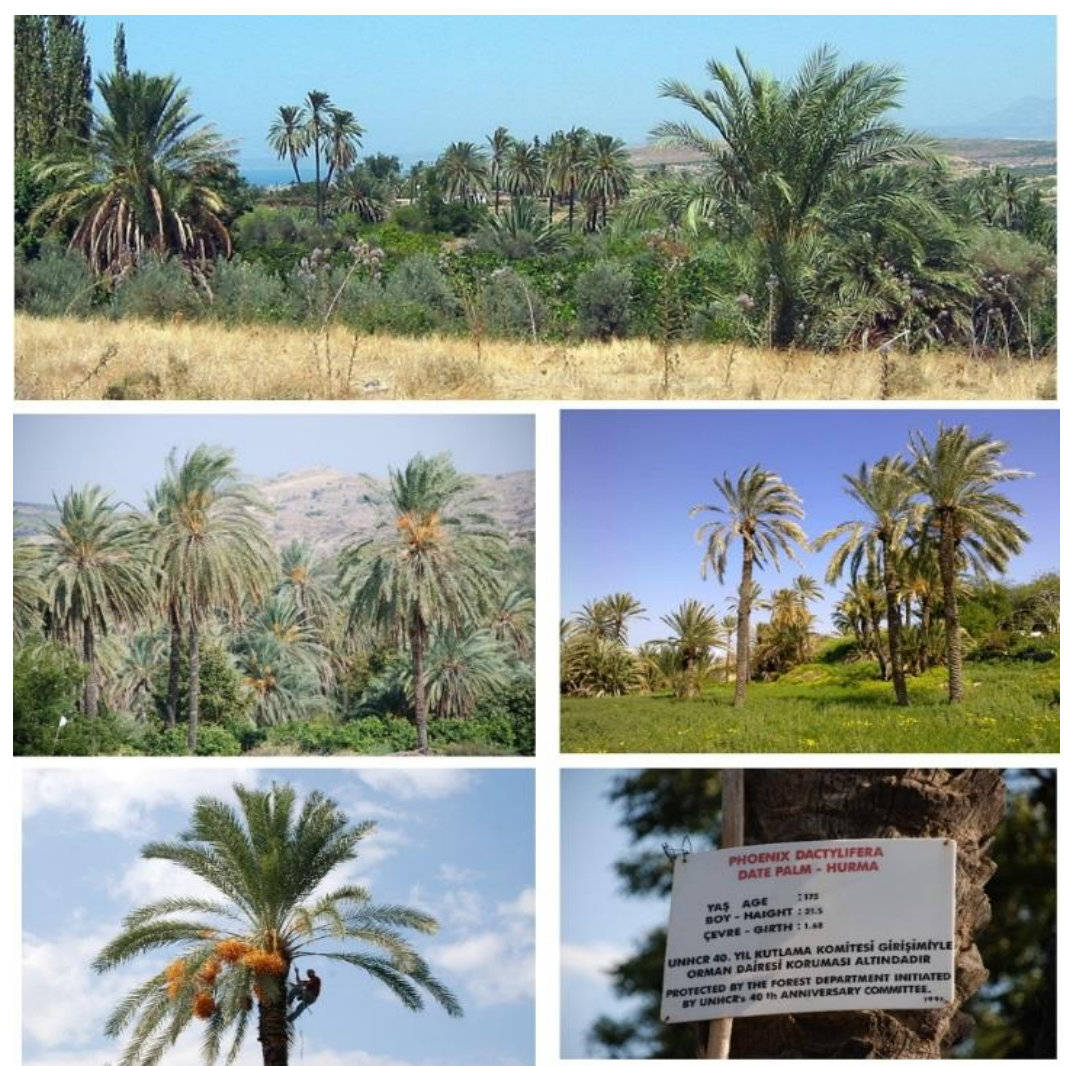

Şekil 3. Lefke bölgesi çalışma alanında doğal ortamlarında bulunan hurma bahçeleri ve ağaçlarından oluşan görüntü 


\section{Meyve Pomolojik Özellikleri ile ilgili Çalışmalar}

Araştırmada ümit verici olarak belirlenen ekonomik öneme sahip hurmaların analizleri için meyve tam olgunluk aşaması olan Tamar döneminde alınmış ve pomolojik özelliklerinin belirlenmesinde; her bir genotipten tesadüfi olarak alınan ortalama 10 meyvede meyve ağırlığı (g), meyve boyu, meyve eni (0.01 mm'ye duyarlı kumpas ile) ve tohum ağırlığı (0.1 g'a duyarlı terazi ile) belirlenmiştir.

\section{BULGULAR VE TARTIŞMA}

Hurma Sayılarına Ait Bulgular
Araştırma sonucunda bölgelere göre ayrılan; Aplıç, Eski Karadağ, Yeni Karadağ, Mandıra, Lefke Cami, Salhane, Alçı Dağı, Rum Mahallesi, Karşıyaka ve Gazi lisesi, Atatürk Parkı ve Bilgiler Tepesi bölgeleri ayrı ayrı değerlendirilmiş ve Lefke bölgesi toplam ağaç sayıları olarak belirlenmiştir. Genel olarak bu ayrılan bölgelerde yapılan toplam ağaç sayısı dişi ve erkek olarak 989 dişi hurma ve 280 erkek hurma ağacı tespit edilmiş ve Çizelge 1 'de ayrıntılı olarak verilmiştir. Bunun yanında aynı plan, yöntem ve metotları kullanarak Lefke bölgesi çevresinde yer alan Gemikonağı, Çamlıköy, Cengizköy, Yedidalga, Doğancı, Yeşilyurt ve Gaziveren köylerindeki hurma ağaçları sayılıp tespit edilmiş ve Çizelge $1^{\prime}$ de ayrıntılı olarak verilmiştir.

Çizelge 1. Lefke Kasabası ve Çevre Köylere Ait Toplam Erkek ve Dişi Hurma Ağaç Sayıları (Adet)

\begin{tabular}{|c|c|c|}
\hline Yöre İsmi & Dişi Ağaç Sayısı & Erkek Ağaç Sayısı \\
\hline Lefke & 989 & 280 \\
\hline Çamlıköy & 54 & 10 \\
\hline Cengizköy & 2 & 3 \\
\hline Gemikonağı & 23 & 16 \\
\hline Yedidalga & 20 & 5 \\
\hline Yeşilyurt & 16 & 4 \\
\hline Doğancı & 20 & 10 \\
\hline Gaziveren & 52 & 8 \\
\hline Toplam & 1176 & 336 \\
\hline
\end{tabular}

\section{Pomolojik Analizlerine Ait Bulgular}

Her bir genotipten tesadüfi olarak alınan 10 meyve üzerinde meyve pomolojik özellikleri yürütülmüştür. Analizler sonucunda elde edilen bulgular Çizelge 2 'de ayrıntılı olarak verilmiştir.

\section{Meyve ağırlı̆̆ı}

Araştırmada yer alan yerel genotipler arasında en yüksek meyve ağırlığı Hur-08 numaralı genotipten (15.29 g) elde edilirken, bunu Hur-05 takip etmiştir (14.55 g). En düşük meyve ağırlığı ise $8.91 \mathrm{~g}$ ile Hur-04' te tespit edilmiştir (Çizelge 2). Bu çalışmada kullanılan yerel hurma genotiplerinde bulunan sonuçlar, lqbal ve ark. (2010) ve Haider ve ark. (2018) tarafından rapor edilen sonuçlar ile karşılaştırıldığında; meyve ağırlı̆ı bakımından sonuçları incelediğimiz meyvelerle uyumlu olduğu belirlenmiştir. Ancak, bizim elde ettiğimiz değerlerin Salomon-Torres ve ark. (2017)'nın Medjool hurma çeşidi üzerinde yaptıkları meyve ağırlığı değerinden düşük olduğu saptanmıştır.

\section{Meyve eni ve boyu}

Yapılan pomolojik analizlerde en geniş meyveyi $26.8 \mathrm{~mm}$ ile Hur-08 vermiştir. Bunu $26.2 \mathrm{~mm}$ ile Hur-05 takip etmiştir. Meyve eni bakımından en düşük değer Hur-01 ve Hur-04 tiplerinde $21.1 \mathrm{~mm}$ olarak belirlenmiştir (Çizelge 2).

Yerel çeşitlerde en uzun meyveyi $41.5 \mathrm{~mm}$ ile Hur-10 vermiştir. Bunu $39.8 \mathrm{~mm}$ ile Hur-09 takip etmiştir. Meyve boyu bakımından en düşük değer Hur-04 tipinde 30.8 mm olarak saptanmıştır (Çizelge 2). 


\section{Tohum ağırlı̆̆ı}

Pomolojik analizlerde tohum ağırlığı açısından en ağır meyveyi 2.84 g ile Hur-10 vermiştir. Bunu 2.30 g ile Hur04 takip etmiştir. Tohum ağırlı̆ı bakımından en düşük değer Hur-02 tipinde 1.36 g olarak ölçülmüştür (Çizelge 2). Bu sonuçlar, lqbal ve ark (2010), Haider ve ark (2018) tarafından bulunan sonuçlar ile karşılaştırıldığında uyumlu bulunmuştur.

Çizelge 2. Pomolojik analiz sonucu elde edilen meyve ağırlığı (g), meyve boyu $(\mathrm{mm})$ ve meyve enine $(\mathrm{mm})$ ait bulgular

\begin{tabular}{ccccc}
\hline Genotip & Meyve Ağırlı̆ı $(\mathrm{g})$ & Meyve Boyu $(\mathrm{mm})$ & Meyve eni $(\mathrm{mm})$ & Tohum ağırlığı $(\mathrm{g})$ \\
\hline Hur-01 & 9.89 & 35.2 & 21.1 & 1.72 \\
Hur-02 & 9.62 & 34.9 & 21.3 & 1.36 \\
Hur-03 & 8.93 & 30.9 & 22.1 & 2.27 \\
Hur-04 & 8.91 & 30.8 & 21.1 & 2.30 \\
Hur-05 & 14.55 & 37.3 & 26.2 & 1.88 \\
Hur-06 & 12.36 & 36.1 & 24.7 & 1.89 \\
Hur-07 & 13.10 & 39.3 & 23.5 & 1.86 \\
Hur-08 & 15.29 & 36.8 & 26.8 & 1.86 \\
Hur-09 & 12.17 & 39.8 & 21.9 & 1.65 \\
Hur-10 & 12.12 & 41.5 & 22.6 & 2.84 \\
\hline
\end{tabular}

Pomolojik analizleri yapılan ve farklı olarak bulunan genotiplerin meyvelerine ait resimler Şekil 4'te verilmiştir.

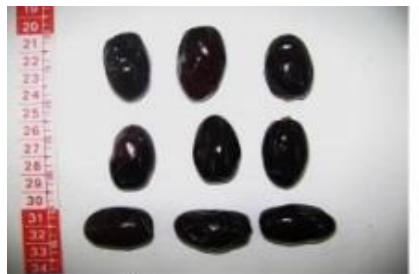

LAÜ-HUR-01

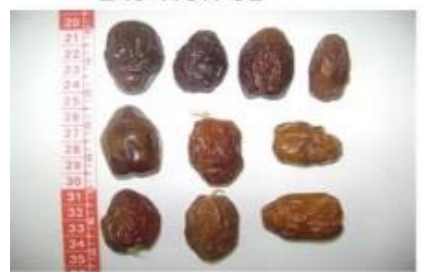

LAÜ-HUR-04

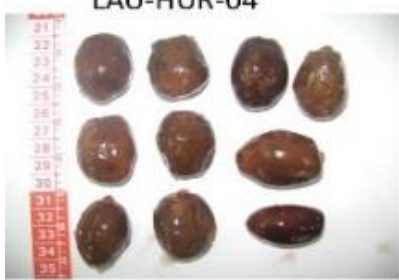

LAÜ-HUR-07

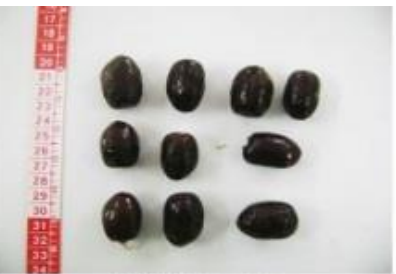

LAÜ-HUR-02

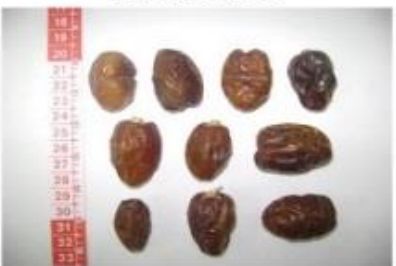

LAÜ-HUR-05

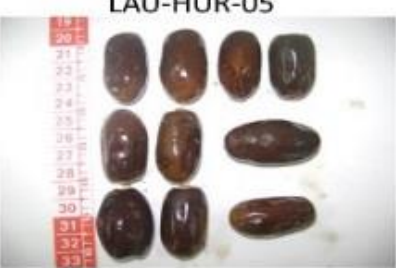

LAÜ-HUR-08

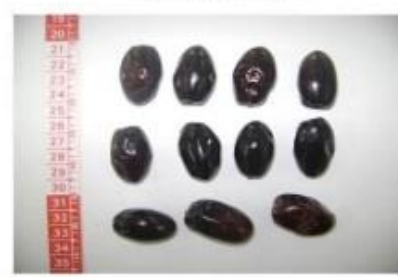

LAÜ-HUR-10

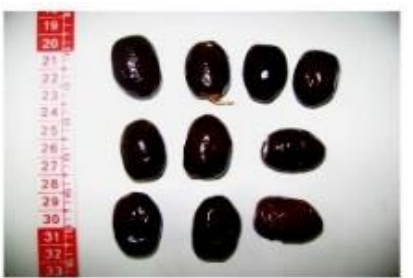

LAÜ-HUR-03

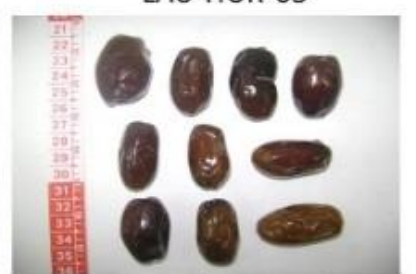

LAÜ-HUR-06

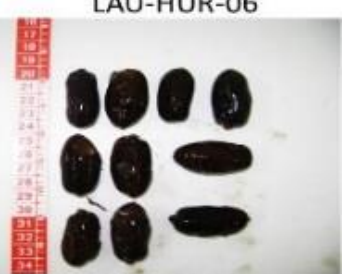

LAÜ-HUR-09

Şekil 4. Bazı genotiplerinin meyvelerinin görünümleri 


\section{SONUÇ}

Sonuç olarak, elde edilen bulgular genel olarak değerlendirildiğinde Hur-08 numaralı genotip meyve özellikleri bakımından değerlendirilmesi gerektiği, bununla beraber bu genotip ve diğer genotiplerin Islah programlarına alınıp ilerleyen yıllarda da izlenmesi ve diğer genotiplerle beraber istatistiksel açıdan da değerlendirilmesi gerekliliği ortaya çıkmıştır. Sonuçlarımız Hur-08 numaralı genotipin tüm dünyaca pazarlanan önemli hurma çeşitleriyle rekabet edebilecek kalitede olduğunu göstermektedir. Yapılan bu çalışma neticesinde adanın mevcut hurma genetik kaynaklarının saptanması, toplanması ve korunması için seleksiyon çalışmalarına önem verilmeli ve yerel hurma üzerinde çalışmalara devam edilmelidir. Bulgularımız yerli hurma gen kaynaklarının potansiyel kaynak olduğunu da ortaya koymuştur. Bu tür çalışmalarda, morfolojik karakterizasyon çalışmalarının yanısıra daha güvenilir sonuçlar elde etmek için moleküler karakterizasyon çalışmalarının yapılmasının yararlı olacağı sonucuna varılmıştır.

\section{TEŞEKKÜR}

Bu çalışmada Lefke Avrupa Üniversitesi, Tarım Bilimleri ve Teknolojileri Fakültesi Dekanlığına ve yardımcı olan değerli öğrencilerimiz Hasan KOLCU ve Halil BAYRAKTAR ve Lefke bölgesindeki hurma hakkında bilgilerinden yararlandığımız ve bölgedeki hurmalarla yıllarca ilgilenmiş Lefke bölgesi sakini Sayın Hurmacı Savaş'a çok teşekkür ederiz.

\section{KAYNAKLAR}

Aladadi WM, Moustafa MF, Alruman SA (2018) Genetic variability among seven cultivars of date palm (Phoenix dactylifera L.) based on embryonic DNA of old fruit. Kuwait J. Sci. 45 (1) pp 108-114.
Al-Shahib W, Marshall RJ (2003) The Fruit of The Date Palm: Its Possible Use as the Best Food for the Future? International Journal of Food Sciences and Nutrition, Volume 54, Number 4, 247-259.

Anonim (2017) IPŞ 2017, İstatistik ve Planlama Şubesi Tarımsal Yapı ve Üretim. KKTC Tarım ve Orman Bakanlığı.

Anonim (2018) FAO; Date Palm Products. http://www.fao.org/docrep/T0681e/T0681e00.Htm\#Con, (Date of access: 14.03.2019).

Anonim (2019a) Date Palm Cultivation. FAO Plant Production And $\begin{array}{llll}\text { Protection } & \text { Paper. } & 156 & \text { Rev. }\end{array}$ http://www.fao.org/3/y4360e/y4360e05.htm\#bm05. (Date of access: 14.03.2019).

Anonim (2019b) Lefke tarihi. http://www.lefkebelediyesi.com/lefkehakk\%C4\%B1nda/lefke-nin-tarihi.html. (Erişim Tarihi: 14.03.2019).

Arias E, Hodder AJ, Oihabi A (2016) FAO support to date palm development around the world: 70 years of activity. Emirates Journal of Food and Agriculture. 28 (1): 1-11

Aslan S, Şanlıer, N, (2018) Hurmanın (Phoenix dactylifera L.) Bileşimi ve Antioksidan Özellikleri. Bes Diy Derg; 46(2):176-182

Faqir N, Muhammad A, Hyder M.Z (2017) Diversity Assessment and Cultivar Identification in Date Palm through Molecular MarkersA Review. Turkish Journal of Agriculture - Food Science and Technology, 5 (12): 1516-1523.

Haider MS, Khan IA, Jaskani MJ, Naqvi SA., Mateen S., Shahzad U, Haider A (2018) Pomological and Biochemical Profiling of Date Fruits (Phoenix dactylifera L.) During Different Fruit Maturation Phases. Pak. J. Bot., 50(3): 1069-1076

Iqbal M, Khan MQ, Munir M, Rehman SU, Rehman HU., Niamatullah M (2010) Effect of Different Pollination Techniques on Fruit Set, Pomological Characters and Yield of Dhakki Date Palm (Phoeiıx dactylifera L) In Dera Ismail Khan, Kp. Sarhad J. Agric. Vol. 26, No. 4

Karut K, Kazak C (2005) Akdeniz Bölgesi'nde Yeni Bir Hurma Ağacı (Phoenix dactylifera L.) Zararlısı: Rynchophorus ferrugineus (Olivier, 1790) (Coleoptera: Curculionidae). Türk. Entomol. Derg., 29 (4): 295-300.

Khan MJU, Billah M, Latif MA (2015) A Study on Different Arabian Date Palm (Phoenix dactylifera L.) Accessions in Bangladesh. The Agriculturists 13 (2): 36-43.

Salomon-Torres R, Ortiz-Uribe N, Villa-Angulo R, Villa-Angulo C, Norzagaray-Plasencia S, García-Verdugo CD, (2017) Effect of pollenizers on production and fruit characteristics of date palm (Phoenix dactylifera L.) cultivar Medjool in Mexico. Turk J Agric For. 41: 338-347

Süleymani A, (2012) Hurma (Phoneix dactylifera L.) Suyu Konsantresi Üretimi ve Bileşim Unsurları. Ankara Üniversitesi, Fen Bilimleri Enstitüsü. Yüksek Lisans Tezi. s: 30 (Basılmış).

Yılmaz N, Alas T, Abak K (2012) Collection of Local Vegetables Genotypes with Their Wild Relatives in North Cyprus. Acta Hort. (ISHS), vol.960, 135-138. 